\title{
Remove Chemical Contaminants from Potable Water by Household Water Treatment System
}

\author{
Teba S. Hussain ${ }^{a^{*}}$, Alaa H. Al-Fatlawi ${ }^{b}$ \\ ${ }^{a}$ Environment Engineering Department, University of Babylon, Hillah, Iraq. \\ ${ }^{b}$ College of Engineering, University of Babylon, Hillah, Iraq. \\ Received 10 April 2020; Accepted 09 July 2020
}

\begin{abstract}
The Main aim of the present study is to manufacture "Low- Cost Water Filter" for purification water and are designed for small water capacity, using readily available material and environmentally friendly such as kaolin clay, and jute fibers. A number of household treatment systems are readily available in the market. They are differing mainly in make and water purification mechanisms utilized. Most of the available household treatment devices are costly and hence there is a need to come up with cheap or affordable treatment technologies. This research was carried out to determine the efficiency of Kaolin-jute fibers filters in improving water impurities. Types of filters that were used during this study are: Filter 1, build with mixing ratio $85 \%$ kaolin clay, and 15\% jute fibers, Filter 2: $80 \%$ kaolin clay, and 20\% jute fibers, Filter 3, 75\% kaolin clay, and 25\% jute fibers. Effectiveness of these filters in decreasing chemical parameters like Hydrogen Ion Concentration (pH), Chloride (Cl), Calcium (Ca), Total Hardness (T.H), Magnesium (Mg), Alkalinity (ALK), Sulfates (SO4), Sodium (Na), and Potassium (K), were 8.7\%, 71.54\%, 70.5\%, 70.5\%, 80.7\%, 77.9\%, 85.5\%, 71.64\%, and 69.6\% respectively. Kaolin-jute fibers filters can produce enough drinking and cooking water for a family of small members due to their flow rates. These filters may be considered for treating contaminated water at household scale in rural areas and places where water is taken directly from the source without treatment.
\end{abstract}

Keywords: Kaolin Clay; Jute Fibers; Potable Water; Household Water.

\section{Introduction}

Water is fundamental for life: both in terms of quantity and quality. Most available water sources (untreated surface water or groundwater) have been impaired by anthropogenic activities and polluted with pathogenic organisms of fecal origin. If not, it may be polluted through storage and transport [1]. Surface water considered an essential source for water supply in many improving countries. Main problem is high focus of clay and organic compounds, suspended solids, and disease-causing microorganisms (such as parasites, viruses, and some bacteria) which can cause symptoms such as cramps, nausea, diarrhea, and provide food and shelter for pathogens [2]. Types of kaolin-jute fibers filters used during this study are: Filter 1, build with mixing ratio 85\% kaolin clay, and 15\% jute fibers, Filter 2: 80\% kaolin clay, and $20 \%$ jute fibers, Filter 3, 75\% kaolin clay, and 25\% jute fibers. Insertion of adsorption media (jute fibers) can easily be done. Jute fibers have large surface areas that contaminants can adhere to Qasim et al. (2000) study [3]. Flow rates were high at early stages of filter use and operation and decreased with an increase in volume of water filtered through [4].

Essential task of any water supply treatment plant is to supply safe water, in enough quantity, degree of treatment

\footnotetext{
* Corresponding author: teba.saadi.ts@gmail.com
} 
depends on raw water type. To achieve the high-quality drinkable water, water must undergo to a chain of treatment processes like flocculation, filtration, coagulation, sedimentation, screening, and disinfection [5]. Aim filtration is to produce low turbidity effluent water. River water that can be very turbid is used for drinking purposes, as is known, turbidity is used to signal water quality [6]. With application of more rigorous turbidity standards and consideration of health effect of microbial polluted in drinking water, more assurance is now given to particle elimination. This shows a necessity for improving performance of water treatment operation, particularly filtration to correspond to the more rigorous turbidity standards [7]. Kaolin-jute fibers filters have high acceptability and low cost, if produced locally, have potential to provide improved drinking water to households in rural areas [8]. Filters can operate consistently regardless of turbidity, $\mathrm{pH}$, and temperature [9].

Some contaminants can easily identify by assessing color, odor, turbidity, and taste of water. However, most of them cannot be easily detected and require testing to reveal whether water is contaminated or not. Thus, contaminants may result in unappealing taste or odor and staining as well as health effects [10]. Color of drinking water is a physical characteristic that cannot be noticed unless it is one of high concentration. Odor is also an indicator for presence of some contamination through odor-free water is not necessarily safe for drinking purposes [11]. Guideline for drinking water quality recommends extremely passable turbidity of $1 \mathrm{NTU}$, however, recommended that preserve filtered water turbidity less than 0.2 NTU can effectively remove Cryptosporidium and Giardia cysts [12]. Water quality should follow up main standards for drinkable water according to WHO, united state environmental protection agency, and Iraq standards number (417) for a year (2001), that acceptable turbidity level $\leq 5$ NTU and preferred less than 1 NTU [13]. Through last contract, a great deal of effort has been expended to study and improve water treatment technology. Much of this effort has concentrated on water filtration. An assurance of filtration results from fact that filtration is final solids-liquid separation step in water treatment [14].

Kaolin-jute fibers filters can, however, be considered a sustainable and transferable technology than can be locally produced and commercially sold [15]. Treating water through use of Kaolin-jute fibers filters does not require addition of chemicals to water avoiding chemical taste and odor problems and creation of disinfection by-products many of which are considered toxic (carcinogenic) in long term. This method of treatment can be recommended for long-term use, notably in a development approach [16]. Presence of organic materials in conjunction with chlorine can form trihalomethanes and other potentially harmful chemicals. Generally, surface water sources have higher turbidity compared to groundwater sources. Turbidity of a surface water source can vary greatly from 1 to 200 NTU (NTU: nephelometric turbidity unit). Immunity in turbidity level is different from children to adult people [17].

\section{Material and Methods}

To begin with step within the fabricate of a filter is acquisition and preparation of the raw materials. One of the focal points of a filter is the neighborhood accessibility of the crude materials fundamental for their make. The major crude materials required are Kaolin clay and Jute fibers. Kaolin-jute fibers filter production flow chart shown in Figure 1.

\subsection{Kaolin Clay}

Iraqi kaolin clay (white kaolin) was chosen, it is found in the form of deposits in AL- Anbar province, $80 \mathrm{~km}$ north of Rutba, Iraqi, southeast of the Akashat Mine for Phosphate. It exists in nature in colors ranging from white to grey depending on the type of impurities found in its composition. Chemical and physical analyses to know the amount of alumina, silica, and other adhesives in the kaolin clay as shown in Table 1.

Table 1. Chemical and physical analyses of kaolin clay

\begin{tabular}{ccc}
\hline & Chemical Analysis & \\
\hline Oxides (\%) & Kaolin & Burned kaolin \\
\hline $\mathrm{SiO}_{2}$ & 47.62 & 54.94 \\
$\mathrm{Al}_{2} \mathrm{O}_{3}$ & 35.86 & 41.375 \\
$\mathrm{Fe}_{2} \mathrm{O}_{3}$ & 0.97 & 1.119 \\
$\mathrm{MgO}$ & 0.33 & 0.381 \\
$\mathrm{CaO}$ & 0.17 & 0.196 \\
$\mathrm{Na}_{2} \mathrm{O}$ & 0.25 & 0.288 \\
$\mathrm{~K}_{2} \mathrm{O}$ & 0.4 & 0.461 \\
Loss after burning & 12.88 & $\ldots$ \\
\hline Promic Matter \% & & 1.2 \\
Temp $\left({ }^{0} \mathrm{C}\right)$ & & 7.5 \\
Specific Weight & & 28.9 \\
Porosity & 2.69 \\
\hline
\end{tabular}




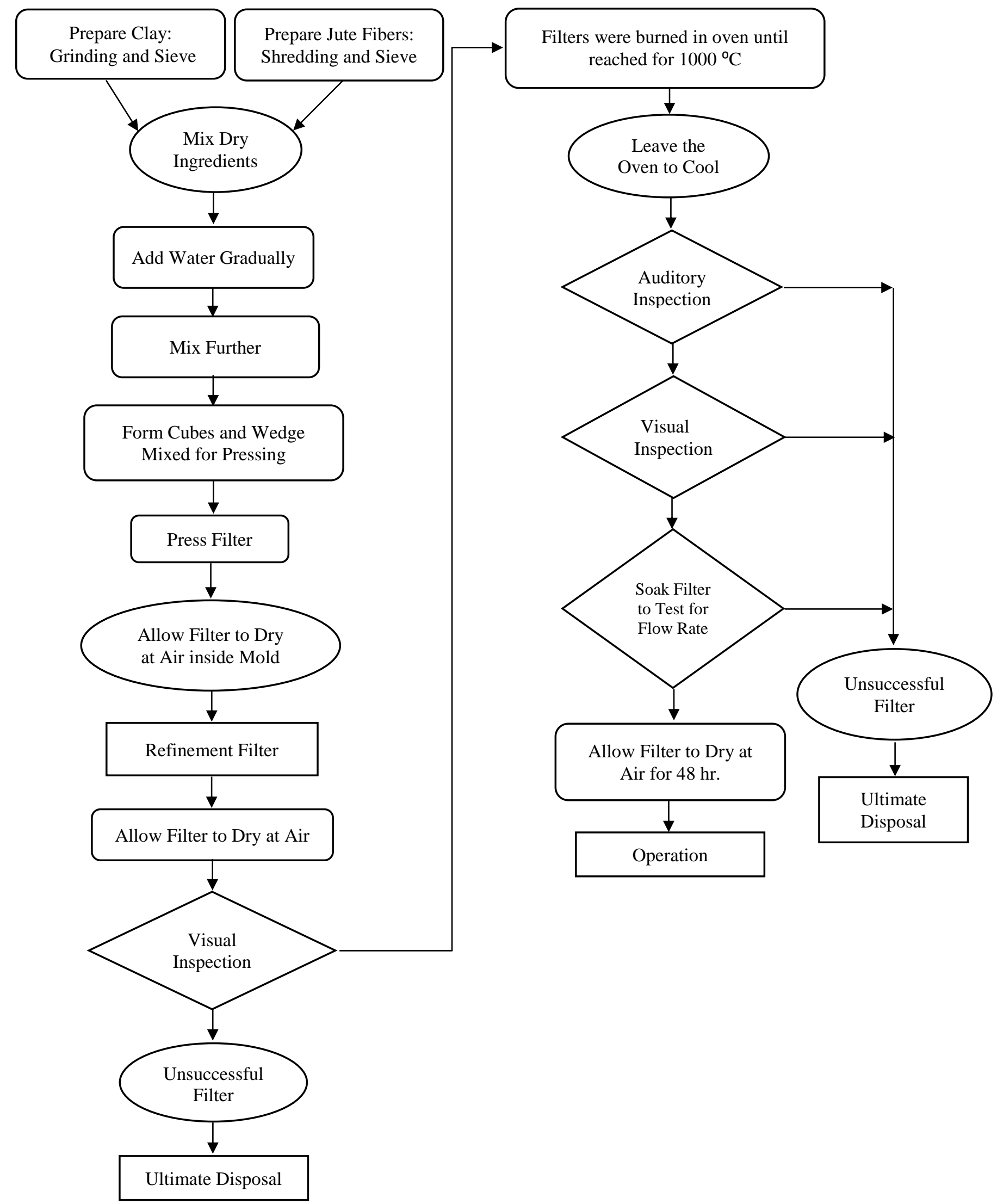

Figure 1. Kaolin-jute fibers filter production flow chart

\section{Kaolin Clay Preparation}

The clay was prepared using the plastic method as follows:

1. Placing the clay in a container with water and mixing well and leave it for 24 hours until all components are completely mixed. 
2. Removing excess water and adding new water, (pure and free of salts).

3. The mixing process is repeated and left for another 24 hours to precipitate and remove the water.

4. After this, the process is repeated three times to remove soluble salts and organic materials.

5. The mixture is mixed and sifted through 100 mesh.

\subsection{Jute Fibers Preparation}

Jute is an important natural fiber taking second place in economic significance only after cotton. It is yellow, brown, and dark gray in color with a natural shine. It grows in hot and humid areas, contains $20 \%$ of Lignin material. The fiber content in the jute varies from 4 to $8 \%$, and is present in the form of spaced bundles arranged in successive circular layers with a single center around the wooden heart, which is the center of the stem. The specific density of jute is estimated at 1.5, it is of little elongation about $1.7 \%$. Moisture gain level is $14 \%$ in standard weather, but in more humid conditions, the absorption rate may reach $23 \%$.

Jute plant grows six to ten feet in height and has no branches. Stem of jute plant is covered with thick bark, which contains fibers. In two- or three-month time, plants grow up and they are cut, tied up in bundles and, kept underwater for several days for fermentation. Thus, stems rot and fibers from the bark become loose. Then pull off fibers from bark, wash very carefully and dry them in sun. Jute fibers are added to clay to create required porosity of fired filter by creating voids within structure of media after material has been burned, which affects the flow rate of filters.

\subsection{Kaolin-jute Fibers Filters Manufacturing and Mold Formation}

\subsubsection{Mixing Percentages}

A different percentage of clay, jute fibers, and water were mixed together as shown in Table 2, to create a uniform composition and to obtain the required flow rate of the Kaolin-jute fibers filters, by trying many times to reach the optimal percentage.

Table 2. Mixing percentages for filters

\begin{tabular}{ccc}
\hline Kaolin-jute Fibers Filters & Kaolin Clay (\%) & Jute Fiber (\%) \\
\hline Filter 1 & 85 & 15 \\
Filter 2 & 80 & 20 \\
Filter 3 & 75 & 25 \\
\hline
\end{tabular}

\subsubsection{Procedure for the Manufacture of a Single Filter}

\section{Equipment:}

1. Kaolin Clay (pounded and sieved);

2. Jute fibers;

3. Water;

4. Gypsum mold.

The procedures of manufacturing are:

1. Place the combined dry materials on the Jute fibers. Dry mix materials by hand. Blend for a few minutes until the whole blend shows up and feels homogenous.

2. Add water and continue to blend by hand. Halt including water to the blend once it gets to be cohesive sufficient to be wedged.

3. Only reason for addition of water is to create a docile mix; water will be removed through firing and drying operation. Therefore, exact amount of water can be left up to discretion of those who wedge clay. Adding too much water will make it difficult to remove a filter from mold.

4. Wedge clay mixture by kneading it aggressively in a rocking motion Proceed until the blend shows up uniform. This step is additionally vital to evacuate any air pockets within the clay. Wedging may be a method that requires an experienced potter to perform appropriately.

5. Form clay into a gypsum mold Slap sides, top, and bottom with a flat hand to create soft surfaces. 


\subsubsection{Method of Drying}

Once the filters were molded, they were dried some time recently let go. Without this step, filters were undergoing dramatic volume change in oven, which cause cracking. Cracking is additionally a hazard amid drying; filters were closely checked amid this step and evacuated from strongly heat and daylight on the off chance that cracking is observed. On the off chance that filters create cracks, damp the complete filter and fix crack zones with excess clay mix. Evacuate them from the daylight to dry in less serious heat.

\subsubsection{Method of Firing}

It is important to ensure filters sufficiently dry before fired at oven. When the filter was fired in an oven, the jute fiber burns out, leaving a network of fine pores during which water can flow during. The filters were burned in the electric oven which dimension $(30 \times 35 \times 48) \mathrm{cm}$, inside, with an electronic control panel to measure the temperature, as shown in Figure 2.
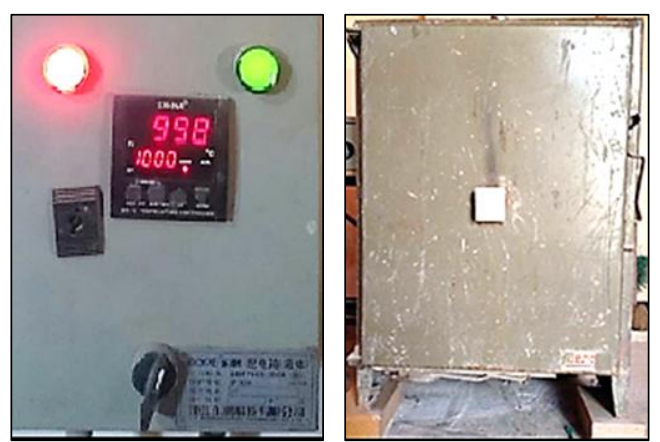

Figure 2. Electric oven with electronic control panel (Ceramic Branch/Faculty of Fine Arts/University of Babylon)

Programmed burning methods were adopted, when reaching to required temperature $1000^{\circ} \mathrm{C}$ (The target temperature for completion of firing), the temperature was fixed for an hour (extra time), to increase the cohesion of the clay particles, as shown in the Table 3.

Table 3. Burning Program

\begin{tabular}{cccc}
\hline Operating time & Time to extinguish & Total time & Temperature \\
\hline $10 \mathrm{sec}$. & $30 \mathrm{sec}$. & $24 \mathrm{hr}$. & $600{ }^{\circ} \mathrm{C}$ \\
$30 \mathrm{sec}$. & $30 \mathrm{sec}$. & $3 \mathrm{hr}$. & $900{ }^{\circ} \mathrm{C}$ \\
$3 \mathrm{hr}$. & $0 \mathrm{sec}$. & $3 \mathrm{hr}$. & $1000{ }^{\circ} \mathrm{C}$ \\
$1 \mathrm{hr}$. & $0 \mathrm{sec}$. & $1 \mathrm{hr}$. & $1000{ }^{\circ} \mathrm{C}$ extra time \\
\hline
\end{tabular}

Then the filters were left inside the oven to cool; the oven door must be left closed to prevent extreme cooling, which can lead to cracks in filters. After that, filters are carefully removed from the oven.

\subsection{Sampling}

The raw water samples used in this study were taken from Shatt Al Hilla river at Al-Hilla city/Iraq Samples of water with different turbidities $(5,15,30,50$, and 80) NTU were taken. Figures 3, 4 and 5 show a map of Hilla River, a general location and exact location of the study area respectively. Filtration was carried out for $3 \mathrm{~h}$ and was done so on the presumption that sufficient water would have been produced for family cooking and drinking needs and to estimate whether there was a variation in chemical polluted removal efficiency at various times and to make necessary modification or recommendations. The samples were transported to the laboratory and assayed to locate the quality of water before and after treatment.

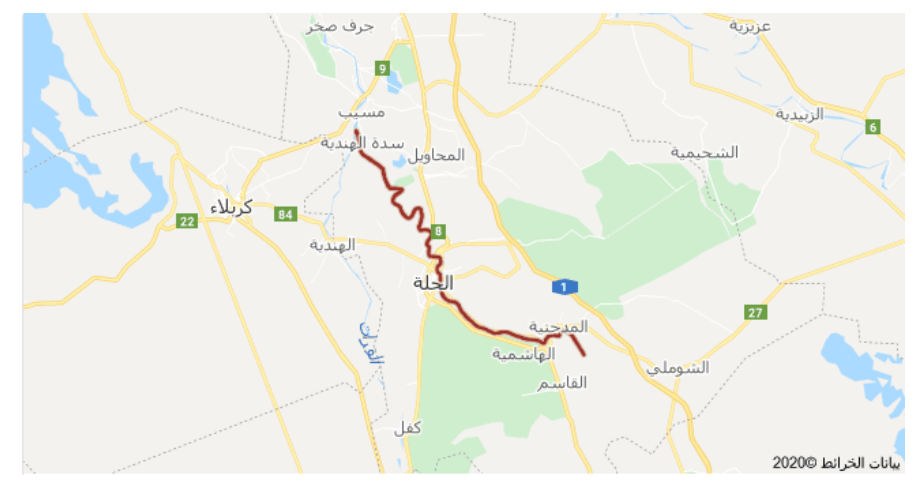

Figure 3. A map of Hilla River 


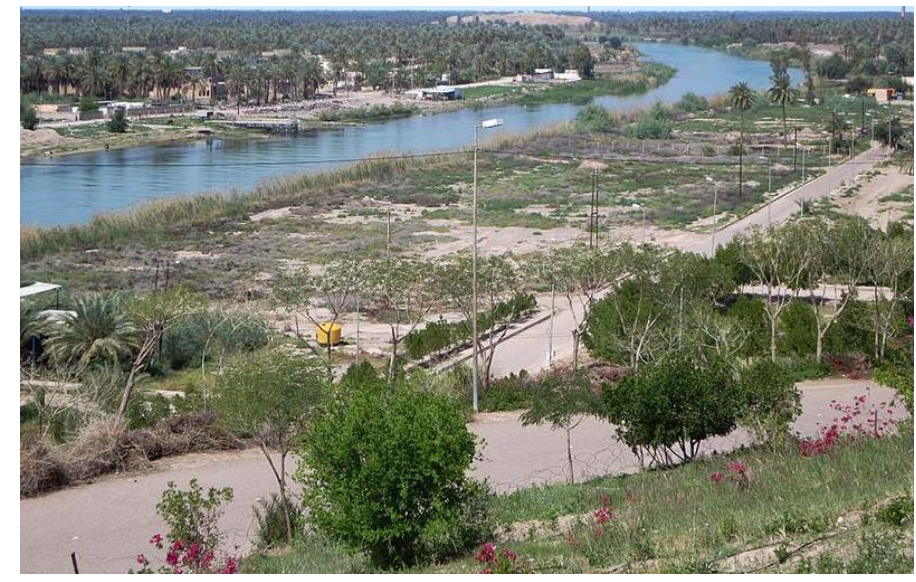

Figure 4. General location

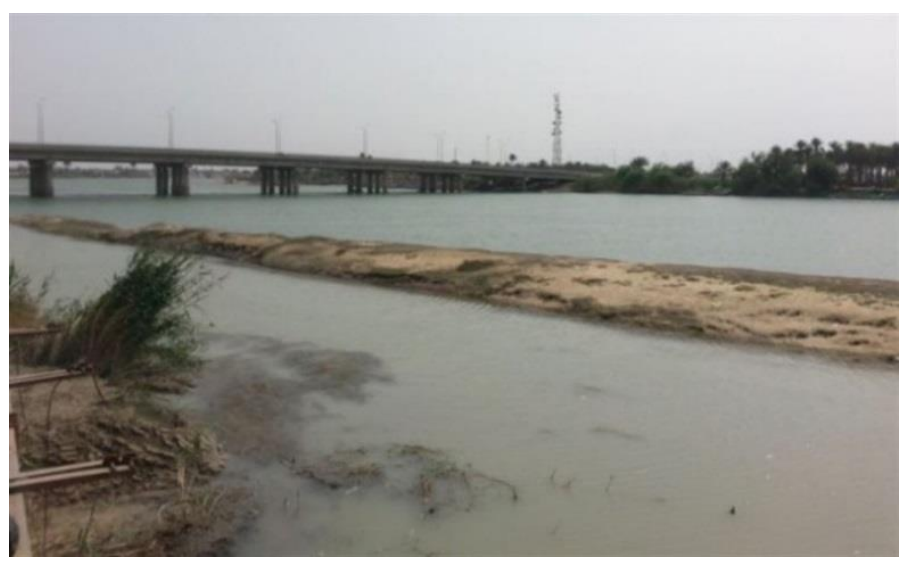

Figure 5. Exact location at $(5,15,30,50,80)$ NTU

\section{Results and Discussion}

\subsection{Flow Rate}

Flow rates were specified by measuring the volume of water (L) collected for each filter per unit time (h). Flow rate depends on the water turbidity conditions, the throughput was measured twice while keeping a constant water level using a volumetric measuring beaker (2L) and the average of the two measurements was taken as flow rate. Figure 6 shows the average flow rate for Kaolin-jute fibers filters.

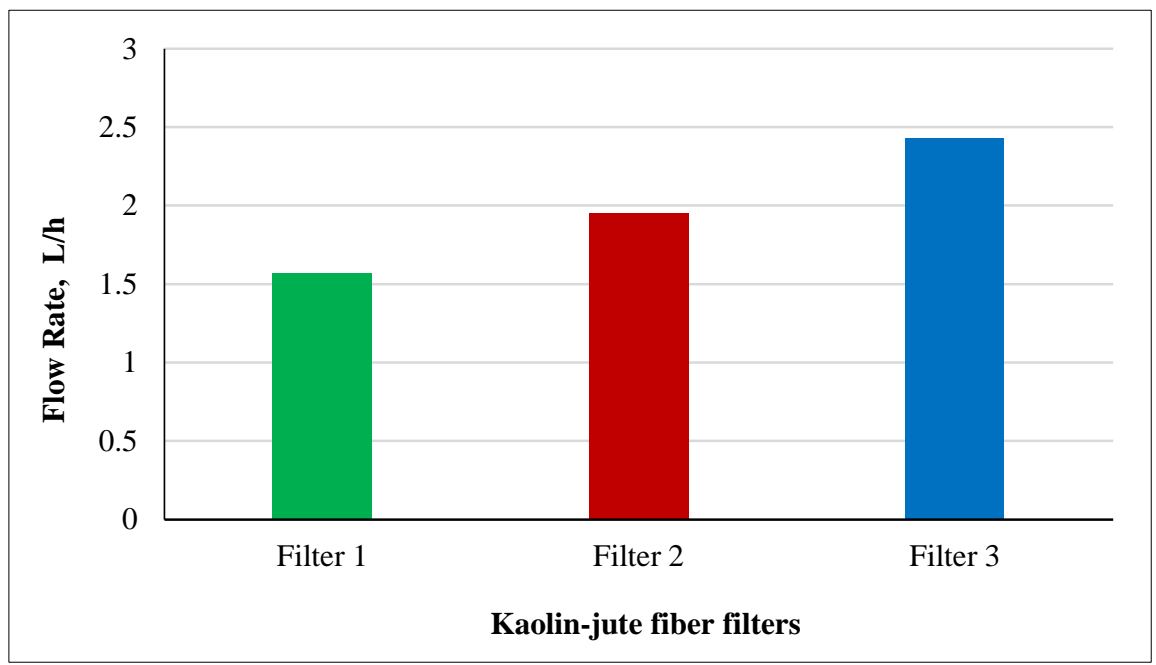

Figure 6. Average flow rate for Kaolin-jute fibers filters

The acceptable flow rate is (1-2) L/hr, according to Henry (2013) [11]. It was clear from Figure 6, the average flow rate for Kaolin-jute fibers filters were: $1.57 \mathrm{~L} / \mathrm{h}, 1.95 \mathrm{~L} / \mathrm{h}$, and $2.43 \mathrm{~L} / \mathrm{h}$ for filter 1, filter 2, and filter 3, respectively. Which was within the acceptable limits of flow rates (1-2) L/hr, according to Brown and Sobsey (2010) [7]; Kallman 
et al. (2011) [18]; Mahlangu et al. (2012) [19]; Ehdaie et al. (2017) [20]; Massoudinejad et al. (2018) [21]; Bulta and Michea (2019) [22] studies. Filters can produce sufficient cooking and drinking water for a household of small members due to their flow rates. These filters may, therefore, be considered for treating polluted water at domestic scale in places where water is taken immediately from the source without treatment.

The flow rates were high at the early stages of filter use and reduced with growing in the volume of water filtered during. Flow rates of the filters were influenced by the turbidity of intake water which was between 5 NTU to 80 NTU. Turbidity determination was useful into scale up the impact of turbidity on the flow rates of filters, it was observed that the flow rates of the filters were lower at higher turbidity levels and higher at lower turbidity levels, but there was a weak negative correlation between the filters' flow rate and turbidity.

Filters with a great number of pores per surface area have a greater flow rate, whereas filters with small pore numbers per surface area have lower flow rates. The porosity for filters 1,2 , and 3 were $40 \%, 51.3 \%$, and $63.1 \%$ respectively, this indicates that the flow rate increases with increasing the percentage of jute fibers.

\subsection{Power of Hydrogen (PH)}

$\mathrm{PH}$ is known as intensity of the acidic or basic character of a solution at a given temperature. As shown in Figure 7. The basic principle of electrometric $\mathrm{pH}$ measurement is the activity of hydrogen ions by potentiometric measurement utilizing a standard hydrogen electrode and a reference electrode. As shown in Figure 8, the $\mathrm{pH}$ for filter 1 was $8.7 \%$ at turbidity $5 \mathrm{NTU}$, and it was gradually decreased to reach $6.67 \%$ at turbidity 80 NTU. Filter 2 their pH ranging from $5.1 \%$ at turbidity $80 \mathrm{NTU}$, to $7.1 \%$, at turbidity 5 NTU respectively. While the value of $\mathrm{pH}$ was the lowest for filter 3 , it was $4.5 \%$ at turbidity $80 \mathrm{NTU}$.

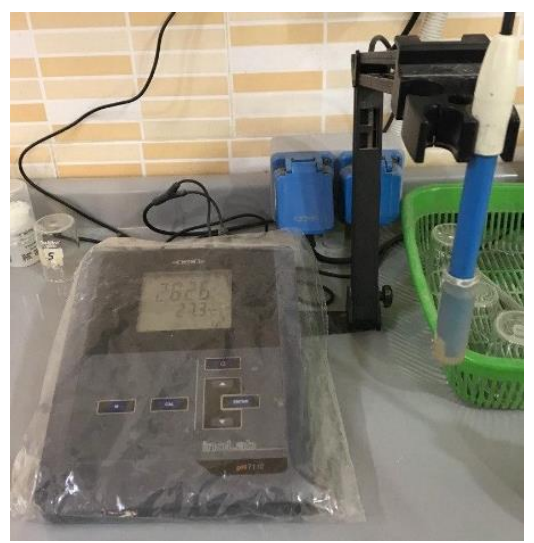

Figure 7. pH measuring device

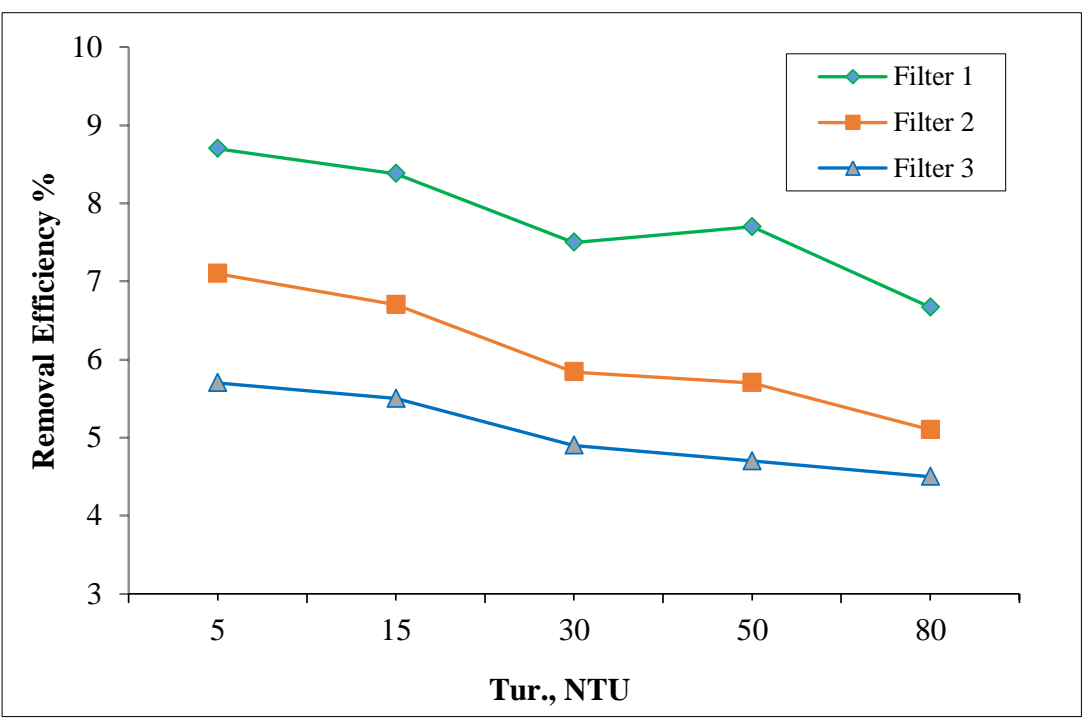

Figure 8. The relationship between removal efficiency and $\mathrm{pH}$, for different turbidities

The great numbers of microbiological particles, if not all, show a negative surface charge over the range of $\mathrm{pH}$ benefit in water treatment, and so do most other aquatic particles and filter media. The variations and changes in $\mathrm{pH}$ and oxidants relative to filtration conditions may result in the dissolving of precipitated particles and/or desorption of material such as natural organic matter. 


\subsection{Total Hardness (T.H)}

Natural total hardness of water relies upon the geological nature of the catchment area. Total hardness is mainly associated with calcium and magnesium ion concentrations regardless of their association with any negative ions. Hardness plays an important role in the allocation of the aquatic biota and many species are specified as indicators for hard and soft waters. Figure 9 shows removal efficiency of the total hardness for all filters.

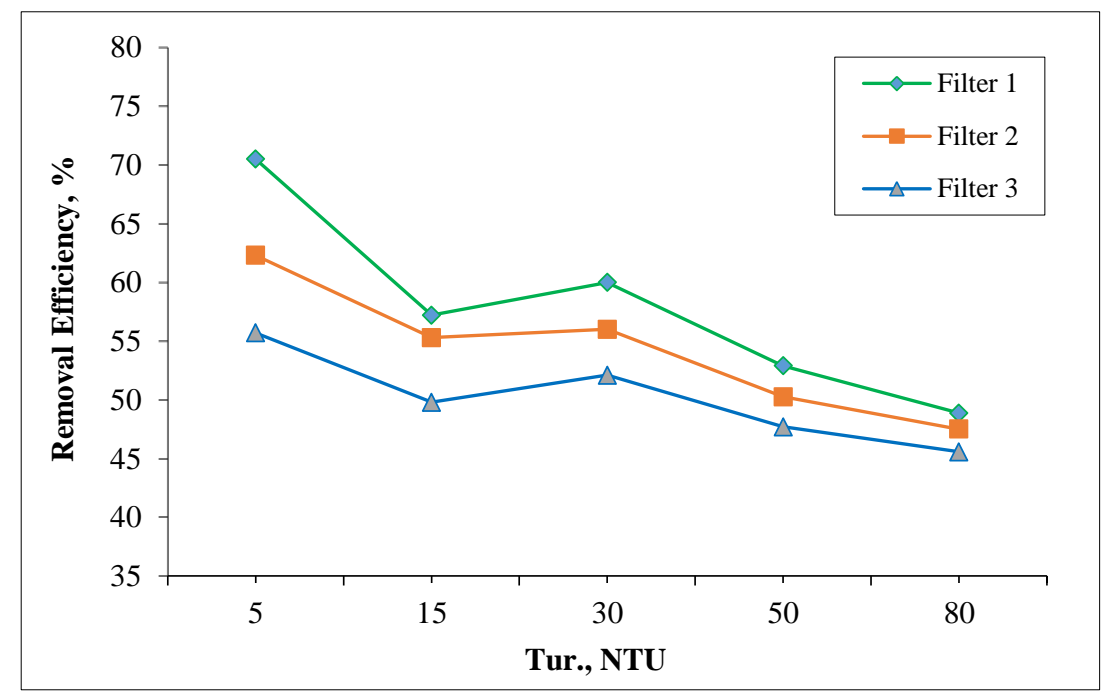

Figure 9. The relationship between removal efficiency and total hardness, for different turbidities

The highest removal efficiency was $70.5 \%$ for filter 1 at turbidity 5 NTU, while filter 3 had the lowest efficiency, which reached to $45.57 \%$ at turbidity 80 NTU. Total harness (temporary: caused by carbonates and bicarbonates of magnesium and calcium cations, and permanent: caused by Sulphates and chlorides of magnesium and calcium of water reflects the total of alkaline metal cations present in it. In case of increasing the hardness value of the alkalinity value, this indicates the presence of other ions such as sodium and potassium as well as calcium and magnesium.

\subsection{Alkalinity (ALK)}

Alkalinity is generally a description of amount of aqueous solution to modify an acid. The term alkalinity in particular is utilized in environmental fields to describe ability of rocks, water, and soil in nature to bind with acids. Figure 10, shows removal efficiency of alkalinity at different turbidities. Degree of alkalinity depends on number of ions with a base effect, particularly the carbonate ion.

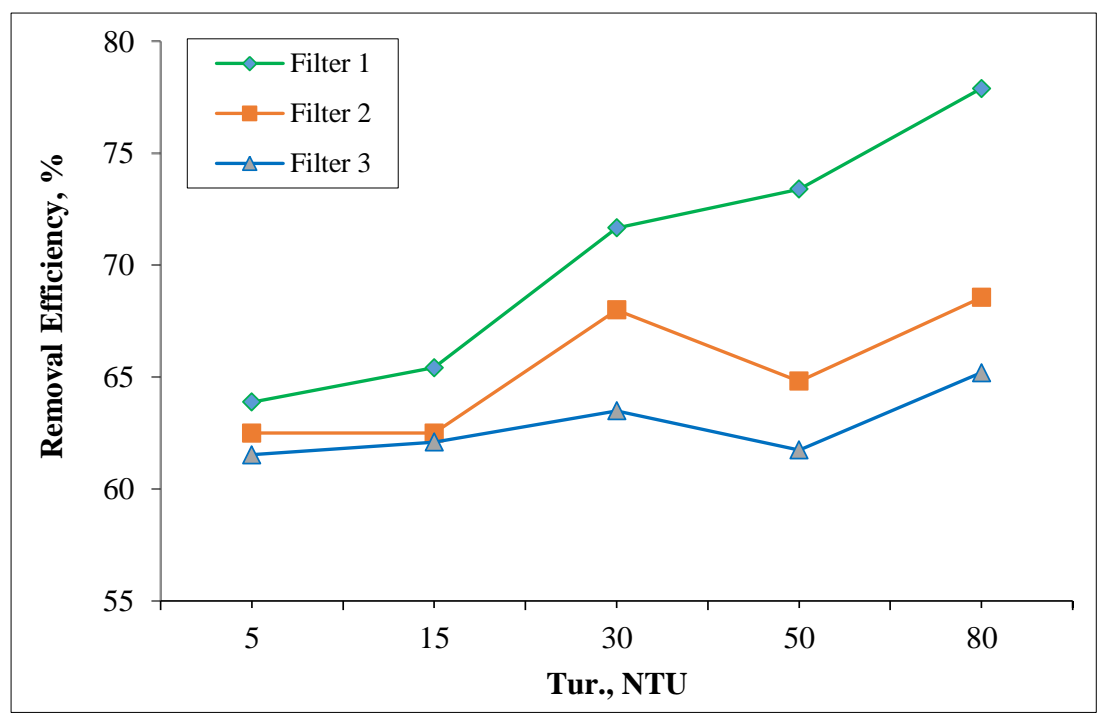

Figure 10. The relationship between removal efficiency and alkalinity, for different turbidities

It is clear from the Figure 10, the highest removal efficiency has occurred at turbidity 80 NTU, for all, where it reached $77.9 \%, 68.56 \%$, and $65.2 \%$, respectively. A high decrease of contaminants was observed when turbidity of intake water was higher. This should be due to the fact that with higher initial contaminant focus in water, turbidity 
was also higher. Initial focus of contaminants in water was found to be linked with removal of contaminant. Mostly, removal of contaminants was found to improve when their initial concentration was higher.

\subsection{Chloride $(\mathrm{Cl})$}

Organic materials are an important source of chloride ion, it is formed when the elemental chlorine $\mathrm{Cl} 2$ (a halogen) acquires an electron or when a compound such as $\mathrm{HCl}$ dissolves in water or other polar solvents. Figure 11, illustrates the removal efficiency of the chloride at different turbidities.

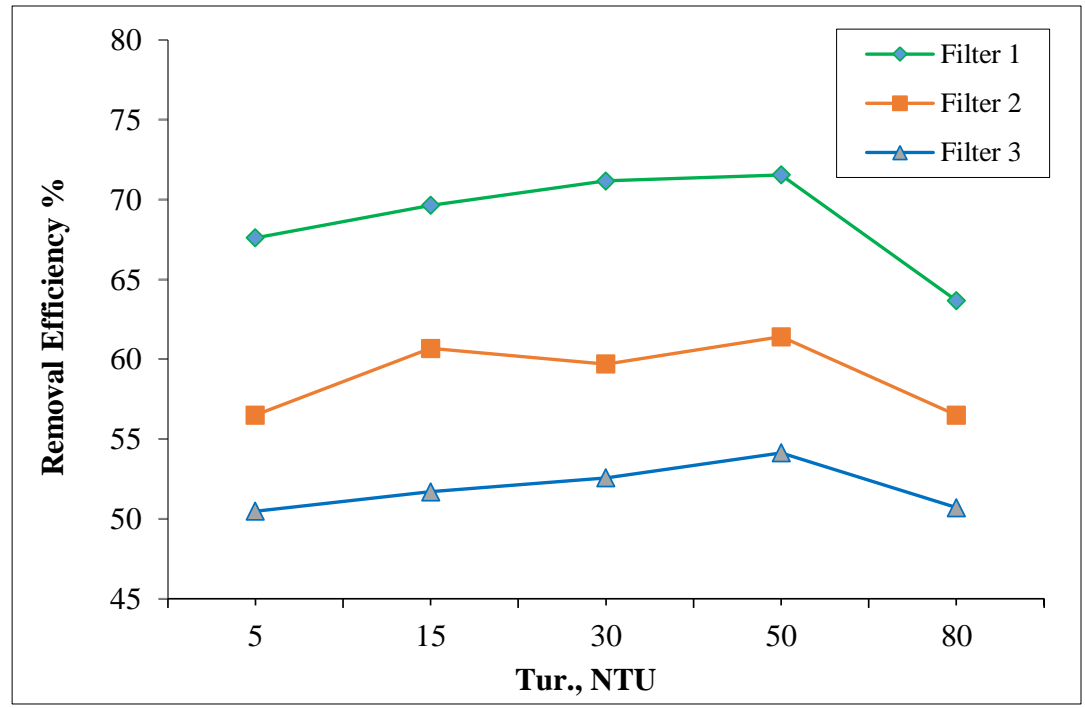

Figure 11. The relationship between removal efficiency and chloride, for different turbidities

From the Figure 11, filter 1 achieved the highest removal efficiency at each turbidity unit, reached to $71.54 \%$ at turbidity 50 NTU, while the removal efficiency for filters 2 ranged between $61.4 \%$ at turbidity 50 NTU, and reduces to reached $50.48 \%$ for filter 3 at turbidity 5 NTU. No clear conclusion could be drawn on how the flow rates were associated with removal of chloride; this indicates that the chloride ion has the ability to form salts with many positive-charged metal ions.

\subsection{Calcium (Ca)}

Calcium is a chemical element symbolized by $\mathrm{Ca}$. It is not found in its free form in nature, it belongs to alkali earth metals. The form of calcium carbonates, which is included in the composition of limestone; and also, in the form of other compounds in plaster metals (Gypsum), anhydrite, fluorite, and apatite, which are also natural calcium raw materials. Figure 12 shows the removal efficiency of calcium for all filters.

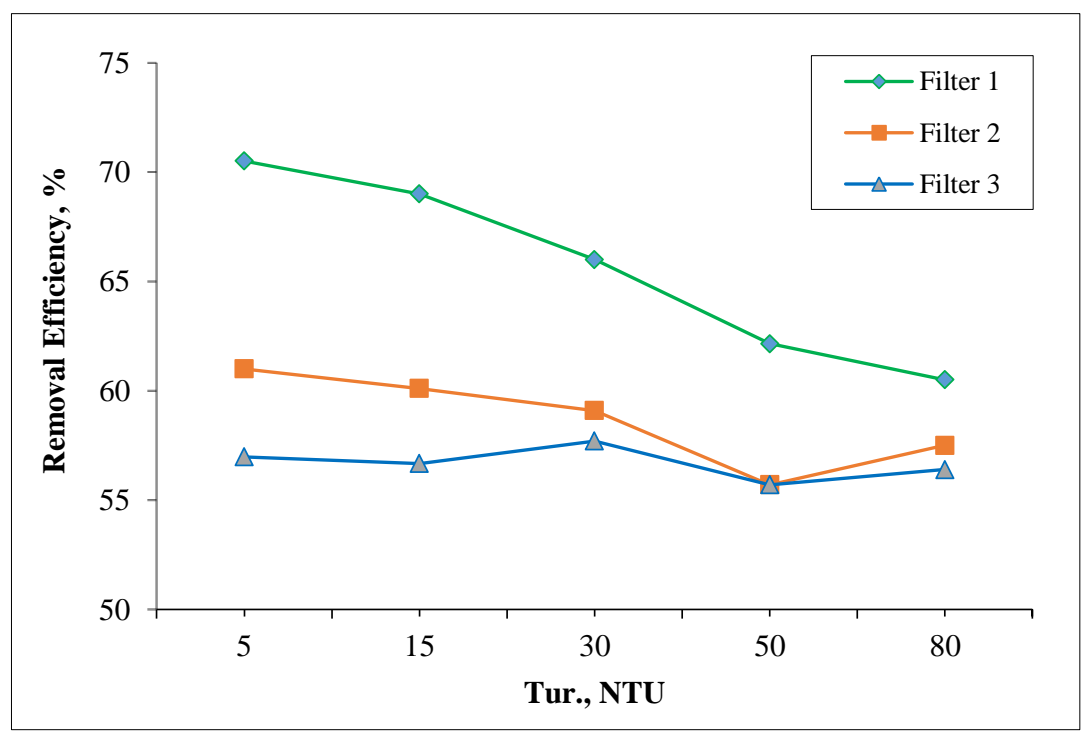

Figure 12. The relationship between removal efficiency and calcium, for different turbidities 
The results indicate that the highest removal efficiency for filter 1 ranged between $70.5 \%$ at turbidity 5 NTU, to $60.5 \%$ at $80 \mathrm{NTU}$, while the lowest removal efficiency for filters 2 and 3 which is equal to $55.7 \%$ at turbidity 50 NTU. This is because adsorption and precipitation as calcium oxide and probably as calcium carbonate were two of the mechanisms that contributed to the removal of calcium from their solution as a layer of oxide and nitride is formed on its surface when exposed to air. Properties are similar to those of its heavier peers in the alkali metal group: strontium and barium. This finding was agreed with Mahlangu et al., (2012) [19]; Bulta and Michea (2019) [22].

\subsection{Magnesium (Mg)}

Magnesium comes after calcium as one of the most important positive ions found in water. The magnesium concentration in water can be found from the results of both hardness and calcium. Magnesium is the product of calcium from total hardness. Figure 13 shows the relationship between removal efficiency and magnesium for all filters.

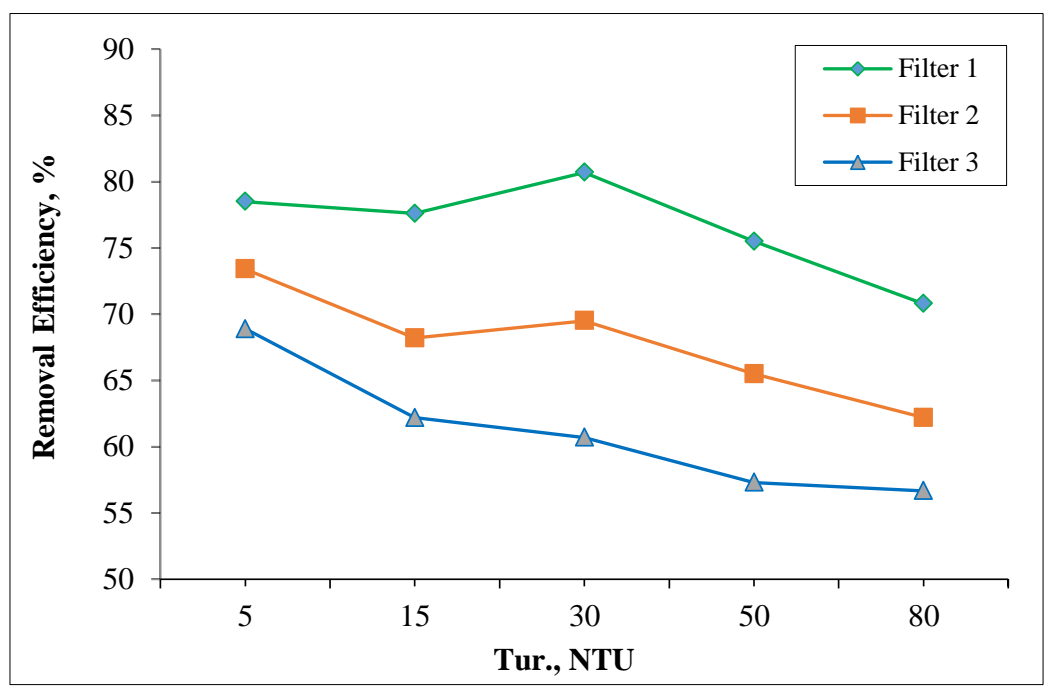

Figure 13. The relationship between removal efficiency and Magnesium, for different turbidities

From the Figure 13 the highest removal efficiency was $80.7 \%$, achieved for filter 1 at turbidity 30 NTU, efficiency was reduced for turbidity 50 and 80 NTU, for all the filters until reached $56.67 \%$ for filter 3 at 80 NTU. Based on above results, the filters removed magnesium to levels with the range of the recommended guideline values. It could be hypothesized that the observed decrease in the removal of magnesium by the filters may be due to the lower measured turbidity of the intake water. This mighty magnesium alteration can be referred to as the emission of exchangeable cations through the mineralization of organic matter and that could be the soil acted as a filtering medium in detained salts. The same result was conducted by Mahlangu et at. (2012) [19]; Bulta and Michea (2019) [22].

\subsection{Sulfate (SO4)}

Sulphate ions generally happen in natural waters. Figure 14, illustrates the removal efficiency of sulfate at different turbidities. Sources of sulphates are mainly sulphate rocks like gypsum (calcium sulphate) and Sulphur minerals like pyrites and also due to water and air pollution.

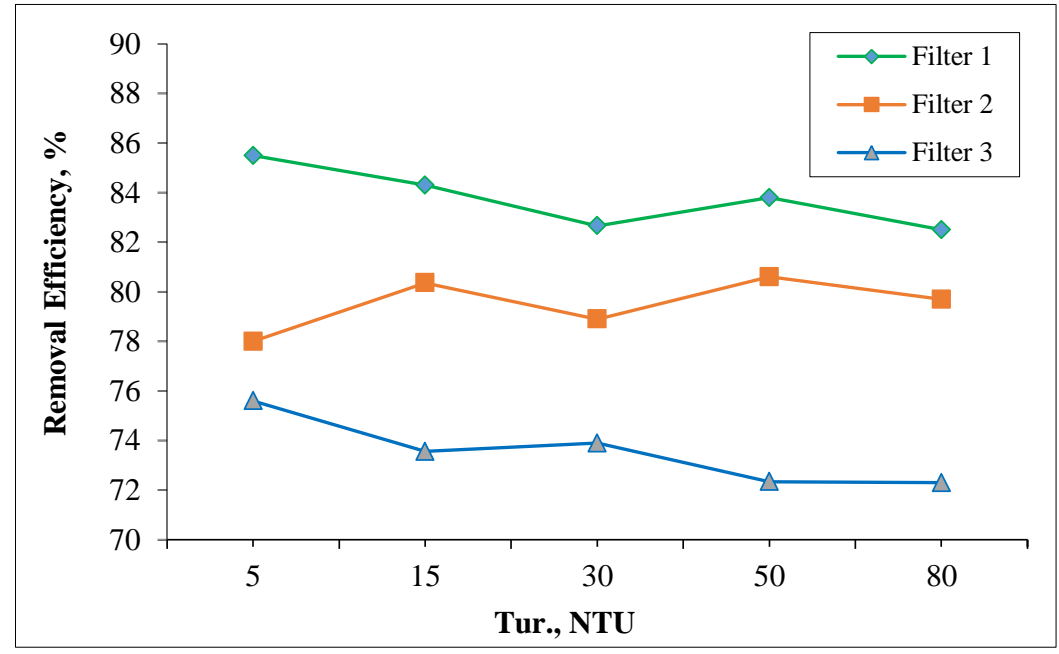

Figure 14. The relationship between removal efficiency and sulfate, for different turbidities 
From the figure above, filter 1 achieved highest removal efficiency at each turbidity unit, especially at turbidity 5 NTU which was equal to $85.5 \%$. The removal efficiency for filters 2 ranged between $80.6 \%$ at turbidity 50 NTU, and decreased to reach $78 \%$ at turbidity $5 \mathrm{NTU}$, while filter 3 achieved the lowest efficacy of removal ranged between $75.6 \%$ turbidity 5 NTU to $72.3 \%$ at turbidity 80 NTU. This is so close to the result $(88.98 \%)$ obtained by Bulta and Michea (2019) [22] through a filter with a mixing ratio (25\% of Sawdust, 5\% of grog, and $70 \%$ of clay). This is because chemical contaminant reduction rates decreased with a growth in an accumulative volume of intake water as filter was utilized, and domestic filter is a system that utilizes an adsorption mechanism to remove chemical contaminants from polluted water.

\subsection{Sodium (Na)}

Sodium is a chemical element symbolized by $\mathrm{Na}$, which is a soft silver-white metal, and present in a number of minerals, the major one being rock salt (sodium chloride). Figure 15 shows removal efficiency of sodium.

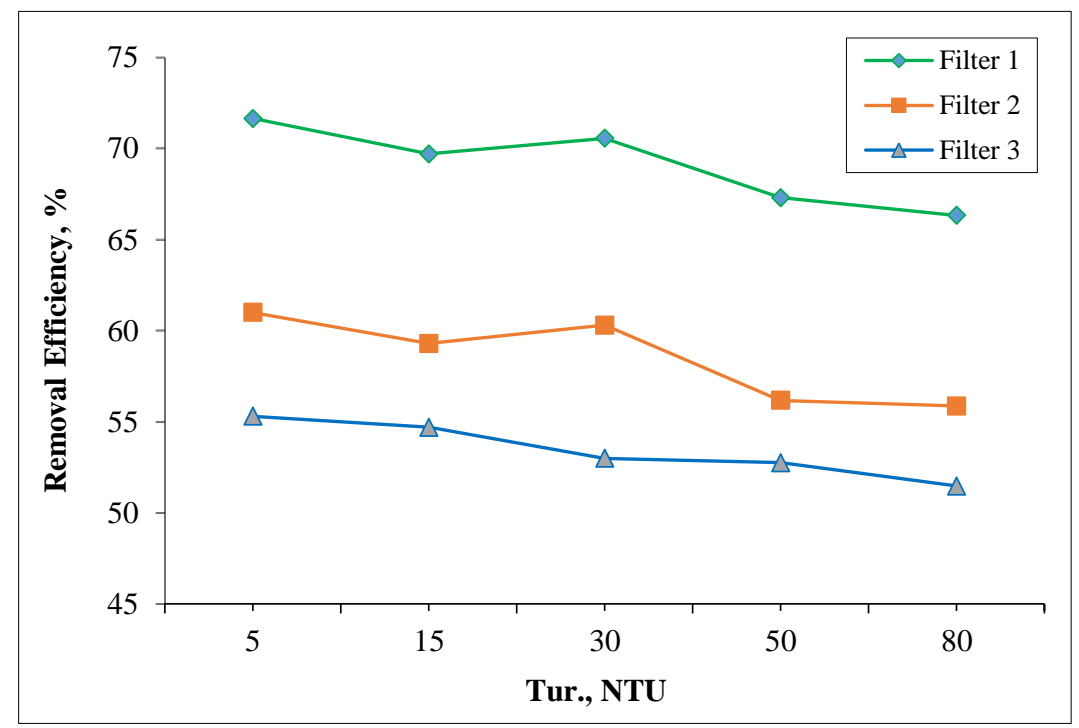

Figure 15. The relationship between removal efficiency and sodium, for different turbidity

The results indicate that the highest removal efficiency for filter 1 was $71.64 \%$ at turbidity 5 NTU, while the removal efficiency for filter 2 ranged between $55.86 \%$ at $80 \mathrm{NTU}$, to $61 \%$ at $5 \mathrm{NTU}$, the lowest removal efficiency for filter 3 ranged between $55.3 \%$ at turbidity $5 \mathrm{NTU}$, to $51.47 \%$ at turbidity $80 \mathrm{NTU}$. This was because filters could remove cations, removal of anions and cations could be due to ion exchange on surface, central cations in clay structure might be replaced with lower charge ions by leaving net negative charge.

\subsection{Potassium (K)}

Potassium is a chemical element symbolized by K. Potassium is a silver-white metal, and soft. Figure 16, illustrates the removal efficiency of potassium at different turbidities for all filters.

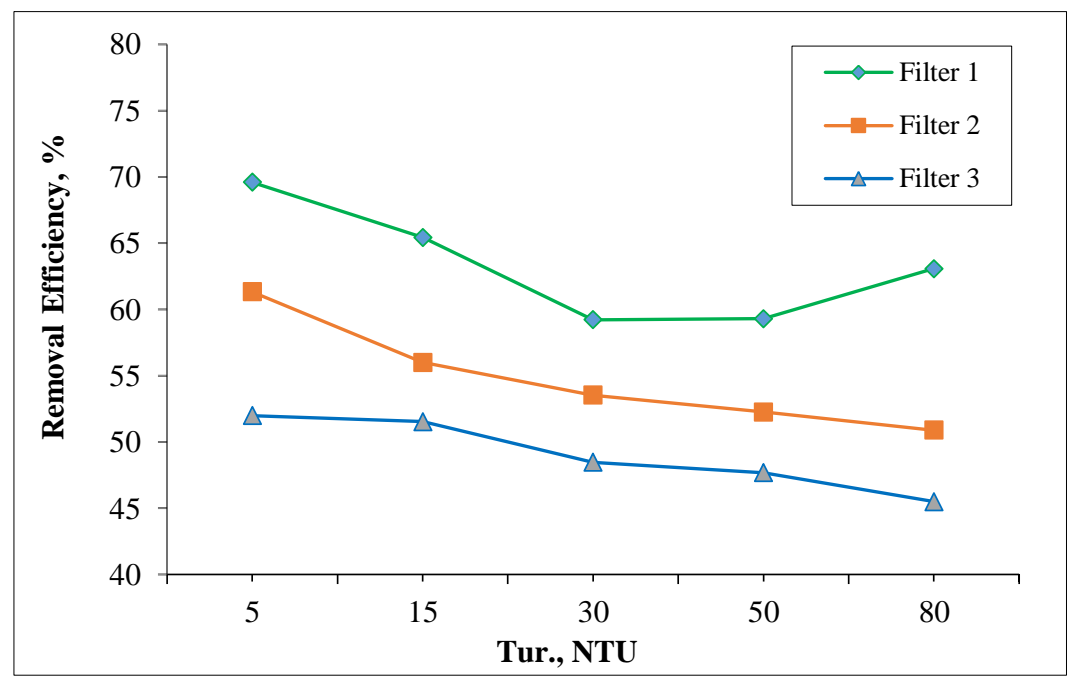

Figure 16. The relationship between removal efficiency and Potassium, for different turbidities 
As shown in Figure 16, filter 1 achieved highest removal efficiency at turbidities 5 NTU which was equal to $69.6 \%$, the removal efficiency for filter 2 ranged between $61.34 \%$ at 5 NTU to $50.9 \%$ at 80 NTU. Filter 3 has the lowest removal efficiency until it reached to $45.5 \%$ at $80 \mathrm{NTU}$. These results are due to the reaction between potassium and oxygen in the air to form a thin layer of white potassium peroxide seconds after exposure. This chemical element was first isolated from potash, ash extracted from some plants. Chemical properties of both potassium and sodium are similar as both are alkali group metals.

\section{Conclusion}

Kaolin-jute fibers filters can operate consistently regardless of turbidity, using readily available material and environmentally friendly such as kaolin clay, and jute fibers. Jute fibers have large surface areas that contaminants can adhere to. The flow rates were high at the early stages of filters use and operation and decreased with an increase in the volume of water filtered through which was between 5 NTU to 80 NTU. The filter had the following flow rates; $1.57 \mathrm{~L} / \mathrm{h}, 1.95$, and $2.43 \mathrm{~L} / \mathrm{h}$, respectively. The results seem to confirm the fact that Kaolin-jute fibers do not require the addition of chemicals to the water avoiding chemical taste and odor problems and the creation of disinfection byproducts many of which are considered toxic (carcinogenic) in the long term. This method of treatment can be recommended for long-term use, notably in a development approach. Kaolin jute fibers filters have high acceptability and low cost, and produced locally. Filters can produce sufficient cooking and drinking water for a family of small members due to their flow rates. These filters may, therefore, be considered for treating polluted water at a household scale in places where water is taken immediately from a source without treatment. The overall performance of the filters in reducing contaminants from drinking water was in the order filter $1>$ filter $1>$ filter 3 .

\section{Acknowledgements}

The authors wish to express their gratitude and sincere appreciation to the laboratory of environmental Engineering Department at Babylon University.

\section{Conflicts of Interest}

The authors declare no conflict of interest.

\section{References}

[1] Dies, Robert William. "Development of a ceramic water filter for Nepal." PhD diss., Massachusetts Institute of Technology, 2003. Available online: https://dspace.mit.edu/handle/1721.1/29553 (accessed on 10 Apr 2020).

[2] World Health Organization. "Combating waterborne disease at the household level." (2007). Available online: https://apps.who.int/iris/bitstream/handle/10665/43621/9789241595223_eng.pdf (accessed on 14 Apr 2020).

[3] Qasim, Syed R., Edward M. Motley, and Guang Zhu. Water works engineering: planning, design, and operation. Prentice Hall, (2000).

[4] Oyanedel-Craver, Vinka A., and James A. Smith. "Sustainable Colloidal-Silver-Impregnated Ceramic Filter for Point-of-Use Water Treatment." Environmental Science \& Technology 42, no. 3 (February 2008): 927-933. doi:10.1021/es071268u.

[5] Sundarakumar, R. "Pilot scale study on floating media filtration for surface water treatment." PhD diss., Asian Institute of Technology, 1996.

[6] Davis, Mackenzie L. Water and wastewater engineering: design principles and practice. McGraw-Hill, 2010.

[7] Brown, Joe, and Mark D. Sobsey. "Microbiological Effectiveness of Locally Produced Ceramic Filters for Drinking Water Treatment in Cambodia." Journal of Water and Health 8, no. 1 (November 9, 2009): 1-10. doi:10.2166/wh.2009.007.

[8] Nnaji, CC, BC Afangideh, and C Ezeh. "Performance Evaluation of Clay-Sawdust Composite Filter for Point of Use Water Treatment.” Nigerian Journal of Technology 35, no. 4 (September 25, 2016): 949. doi:10.4314/njt.v35i4.33.

[9] Russell D. L. "Filtration Theory and Practice." Practical Wastewater Treatment (April 10, 2006): 135-148. doi:10.1002/0470067926.ch8.

[10] Ren, Dianjun, Lisa M. Colosi, and James A. Smith. "Evaluating the Sustainability of Ceramic Filters for Point-of-Use Drinking Water Treatment." Environmental Science \& Technology 47, no. 19 (September 18, 2013): 11206-11213. doi:10.1021/es4026084.

[11] Henry, Michael, Siri Maley, and Khanjan Mehta. "Designing a Low-Cost Ceramic Water Filter Press." International Journal for Service Learning in Engineering, Humanitarian Engineering and Social Entrepreneurship 8, no. 1 (June 4, 2013): 62-77. doi:10.24908/ijsle.v8i1.4532. 
[12] World Health Organization, WHO, and World Health Organization Staff. Guidelines for Drinking-Water Quality. Vol. 1. World Health Organization, 2004.

[13] Tebbutt, Thomas Hugh Yelland. Principles of water quality control. Elsevier, 1997.

[14] Brown, Joe, Dana Loomis, and Mark D. Sobsey. "Local Drinking Water Filters Reduce Diarrheal Disease in Cambodia: A Randomized, Controlled Trial of the Ceramic Water Purifier." The American Journal of Tropical Medicine and Hygiene 79, no. 3 (September 1, 2008): 394-400. doi:10.4269/ajtmh.2008.79.394.

[15] Bulta, Alemu Lelago, and Geremew Arega W. Micheal. "Evaluation of the Efficiency of Ceramic Filters for Water Treatment in Kambata Tabaro Zone, Southern Ethiopia." Environmental Systems Research 8, no. 1 (January 5, 2019). doi:10.1186/s40068-018-0129-6.

[16] Collivignarelli, Maria, Alessandro Abbà, Ilaria Benigna, Sabrina Sorlini, and Vincenzo Torretta. "Overview of the Main Disinfection Processes for Wastewater and Drinking Water Treatment Plants." Sustainability 10, no. 2 (December 31, 2017): 86. doi:10.3390/su10010086.

[17] Zereffa, Enyew Amare, and Tesfaye Betela Bekalo. "Clay Ceramic Filter for Water Treatment." Materials Science and Applied Chemistry 34, no. 1 (January 1, 2017). doi:10.1515/msac-2017-0011.

[18] Kallman, Erin N., Vinka A. Oyanedel-Craver, and James A. Smith. "Ceramic Filters Impregnated with Silver Nanoparticles for Point-of-Use Water Treatment in Rural Guatemala.” Journal of Environmental Engineering 137, no. 6 (June 2011): 407415. doi:10.1061/(asce)ee.1943-7870.0000330.

[19] Mahlangu, Themba O., Bhekie B. Mamba, and Maggie NB Momba. "A comparative assessment of chemical contaminant removal by three household water treatment filters." Water SA 38, no. 1 (2012): 39-48. doi: 10.4314/wsa.v38i1.6.

[20] Ehdaie, Beeta, Chloe T. Rento, Veronica Son, Sydney S. Turner, Amidou Samie, Rebecca A. Dillingham, and James A. Smith. "Evaluation of a Silver-Embedded Ceramic Tablet as a Primary and Secondary Point-of-Use Water Purification Technology in Limpopo Province, S. Africa." Edited by Zhi Zhou. PLOS ONE 12, no. 1 (January 17, 2017): e0169502. doi:10.1371/journal.pone.0169502.

[21] Massoudinejad, Mohamadreza, Yalda Hashempour, and Hamed Mohammad. "Evaluation of Carbon Aerogel Manufacturing Process in Order to Desalination of Saline and Brackish Water in Laboratory Scale." Civil Engineering Journal 4, no. 1 (February 7, 2018): 212. doi:10.28991/cej-030980.

[22] Bulta, Alemu Lelago, and Geremew Arega W. Micheal. "Evaluation of the Efficiency of Ceramic Filters for Water Treatment in Kambata Tabaro Zone, Southern Ethiopia." Environmental Systems Research 8, no. 1 (January 5, 2019). doi:10.1186/s40068-018-0129-6. 